\title{
O sistemismo de Bunge como base teórico- metodológica para pesquisa em Ciência da Informação
}

\author{
Luciana Mara Silva \\ Doutoranda; Universidade Federal de Santa Catarina (UFSC) e Universidade do Sul de Santa Catarina \\ (Unisul); \\ luciana.mara@unisul.br \\ William Barbosa Vianna \\ Doutor; Universidade Federal de Santa Catarina (UFSC); \\ william.vianna@ufsc.br \\ Vinícius Medina Kern \\ Doutor; Universidade Federal de Santa Catarina (UFSC); \\ vmkern@pq.cnpq.br
}

\begin{abstract}
Resumo: O objetivo do estudo é aprofundar aspectos epistemológicos da Ciência da Informação $(\mathrm{CI})$ a partir das contribuições do pensamento de Bunge. Justifica-se pela natureza interdisciplinar da CI e sua constante necessidade de interação com outras áreas de conhecimento. Trata-se de um ensaio teórico a partir da análise de conceitos da área de CI e a proposta sistemista de Bunge. $\mathrm{O}$ estudo é complementado com a aplicação dos fundamentos do sistemismo em pesquisas sistemistas, uma descritiva e outra explicativa, sobre repositórios institucionais de acesso aberto, exemplificando a condução de pesquisa sob a operação epistêmica fundamental do sistemismo: a redução ao sistema.
\end{abstract}

Palavras-chave: Sistemismo. Mario Bunge. Realismo científico. Epistemologia. Metodologia da pesquisa.

\section{Introdução}

A epistemologia ou teoria do conhecimento estuda a validade e legitimidade do conhecimento. É um ramo da filosofia que "[...] indaga pela possibilidade, origem, essência, limites, pelos elementos e pelas condições do conhecimento." (CHINAZZO, 2013, p. 31-32). Busca responder o que é conhecimento e o que podemos conhecer. A palavra conhecimento tem sua origem no latim cognitio, o que pressupõe a relação de um sujeito e um objeto. "O conhecimento é o ato, o processo pelo qual o sujeito se coloca no mundo, e, com ele, estabelece uma 
ligação. Por outro lado, o mundo é o que torna possível o conhecimento ao se oferecer a um sujeito apto a conhecê-lo." (ARANHA; MARTINS, 1999, p. 48).

Tendo em vista o caráter interdisciplinar da Ciência da Informação (CI), é fundamental um constante aprofundamento do debate epistemológico, tendo em vista possíveis ampliações de fronteiras e assimilação de conceitos e abordagens compatíveis e coerentes com o desenvolvimento da área.

Nesse sentido, o objetivo do artigo é apresentar a pesquisa sistemista de Bunge (1997, 2000, 2003, 2004) como possibilidade teórica e metodológica realista para pesquisas na $\mathrm{CI}$, com características úteis ao desenvolvimento da área. O sistemismo é uma visão de mundo que pode ser utilizada como base nos estudos empíricos de qualquer sistema, incluindo sistemas técnicos e sociais que tenham foco em informação, sejam unidades ou serviços de informação, bases de dados, sistemas de informação etc. Logo, é uma teoria com aplicabilidade em diversas áreas, incluindo a CI.

Para alcançar o objetivo proposto, foi realizada uma revisão da literatura a partir de um levantamento bibliográfico, apresentando-se os dados por meio de uma discussão teórica seguida da aplicação dos fundamentos discutidos por meio de duas pesquisas, uma descritiva e outra explicativa. Entende-se o método revisão da literatura como uma revisão genérica, que permite uma análise cronológica, conceitual ou temática de fontes amplas de pesquisa (GRANT; BOOTH, 2009).

$\mathrm{Na}$ seção 2, busca-se identificar aproximações e divergências nos diferentes conceitos de CI e informação adotados na literatura. A sessão 3 aborda a demarcação científica segundo Bunge. Na sequência, aborda-se o sistemismo de Bunge relacionado ao seu parceiro epistemológico, o realismo científico, depois comparado a abordagens filosóficas rivais, o individualismo e o holismo, e finalmente exposto em seus construtos fundamentais: os postulados, o modelo CESM de sistema e as regras metodológicas (seção 4). Na seção 5 é apresentada a aplicação prática da pesquisa sistemista em repositórios institucionais vistos como sistemas de informação. As considerações finais são dadas na seção 6 . 


\section{Ciência da Informação: objeto de estudo e tendências da área}

A CI tem seu surgimento frequentemente associado à constatação do excesso de informação e à dificuldade para acessá-la e recuperá-la (BUSH, 1945). Shera e Cleveland (1977), Pinheiro (2005) e Rabello (2012) concordam com a definição de CI enunciada por Borko (1968, p. 5, tradução nossa) a partir da conferência no Georgia Institute for Technology em 1961:

É uma ciência interdisciplinar que investiga as propriedades e comportamento da informação, as forças que governam os fluxos e o uso da informação e as técnicas, tanto manuais quanto mecânicas, de processamento da informação, visando sua armazenagem, recuperação, e disseminação ótimas ${ }^{1}$.

Extraímos dessa definição palavras-chave que nos remetem à ideia de trabalhar a informação como "uma coisa" dotada de objetividade: informação como comportamento, fluxos, técnicas de processamento, armazenagem, recuperação e disseminação. Saracevic (1966) define a CI como um campo com problemas que são propostos e métodos para solucioná-los, que engloba tanto a pesquisa científica quanto a prática profissional. Identifica três características que constituem a razão da existência e da evolução da CI: (1) é interdisciplinar; (2) está ligada à tecnologia da informação; (3) tem um importante papel a desempenhar por sua forte dimensão social e humana, que ultrapassa questões tecnológicas. Infere-se que os problemas vinculados ao objeto de estudo informação estão se moldando na relação humano-tecnológica. Pinheiro (1998) entende que a CI tem como nascente o processo de comunicação e informação em diferentes contextos. A autora aponta para uma reconciliação da área com o humanismo para constituição de uma nova categoria de Ciências Sociais: as ciências tecno-culturais:

[...] a Ciência da Informação, gestada sob o signo da guerra e herdeira da tecnologia, parece buscar a reconciliação com o humanismo quase perdido [...], para a constituição de uma nova categoria de ciências sociais - as ciências tecno-culturais. (PINHEIRO, 1998, p. 33).

Com base nos autores aqui citados, podemos evidenciar como pontos convergentes: (1) a informação como objeto de estudo da área (ainda que não exista um consenso na definição do termo); (2) a interdisciplinaridade - sua 
relação com outras áreas. Não há um conceito comum para CI; há diversos entendimentos que podem subsidiar as diferentes influências pragmáticas da área (LIMA; ALVARES, 2012). Não só há mudanças paradigmáticas; há bastante diversidade e divergência entre os proponentes de visões epistemológicas da área sobre o que é CI. Percebe-se que o conceito de CI não se admite isoladamente, ele está intrinsecamente conectado a outros conceitos, conforme as percepções conceituais dos autores como: informação, conhecimento, documento, tecnologia, comunicação entre outros. São decisões validadas por determinados participantes de uma escola de pensamento (SALDANHA, 2008).

Nesse sentido Silva, J. (2014) sumaria a concepção de Capurro (2003) de três paradigmas subordinados aos elementos físico, cognitivo e social da informação, conforme o Quadro 1.

Quadro 1 - Paradigmas na CI

\begin{tabular}{|c|c|c|c|}
\hline & Paradigma físico & Paradigma cognitivo & Paradigma social \\
\hline $\begin{array}{l}\text { Período } \text { de } \\
\text { iniciação }\end{array}$ & Fins da década de 1940. & Fins da década de 1970. & Início da década de 1990. \\
\hline $\begin{array}{l}\text { Principais } \\
\text { representant } \\
\text { es }\end{array}$ & $\begin{array}{l}\text { Shannon e Weaver } \\
\text { (1949) e Mooers (1951, } \\
\text { 1960). }\end{array}$ & $\begin{array}{lr}\text { De May (1977); Brookes } \\
(1977 ; \quad 1980) ; \quad \text { Belkin } \\
(1980) ; & \text { Ingwersen } \\
(1992) . & \end{array}$ & $\begin{array}{l}\text { Hjørland e Albrechtsen } \\
\text { (1995), Hjørland (2002); } \\
\text { Capurro (2003). }\end{array}$ \\
\hline Enfoques & $\begin{array}{l}\text { Sistema de informação e } \\
\text { processos tecnológicos } \\
\text { no âmbito da organiza- } \\
\text { ção e tratamento da } \\
\text { informação. }\end{array}$ & $\begin{array}{lr}\text { Usuário e } & \text { processos } \\
\text { psicológicos } & \text { para } \\
\text { organização, tratamento } \\
\text { e serviços } \\
\text { informação. }\end{array}$ & $\begin{array}{l}\text { Domínio e processos } \\
\text { sociais na construção } \\
\text { coletiva, interacionista e } \\
\text { dialógica da informação. }\end{array}$ \\
\hline $\begin{array}{l}\text { Assuntos } \\
\text { que } \\
\text { englobam os } \\
\text { estudos de } \\
\text { paradigmas }\end{array}$ & $\begin{array}{l}\text { Estudo de usuários - } \\
\text { abordagem quantitativa. } \\
\text { Recuperação da infor- } \\
\text { mação - enfoque técnico } \\
\text { no sistema de } \\
\text { informação. } \\
\text { Estudos sobre organiza- } \\
\text { ção e representação da } \\
\text { informação sob o } \\
\text { enfoque técnico. }\end{array}$ & $\begin{array}{l}\text { Estudo de usuários - } \\
\text { abordagem qualitativa } \\
\text { Recuperação da infor- } \\
\text { mação - enfoque na } \\
\text { função do sistema para o } \\
\text { usuário da informação a } \\
\text { partir do uso de para- } \\
\text { digmas como behavio- } \\
\text { rista, processamento da } \\
\text { informação e funciona- } \\
\text { lista-estrutural. } \\
\text { Estudos sobre organiza- } \\
\text { ção e representação da } \\
\text { informação para o } \\
\text { usuário. }\end{array}$ & $\begin{array}{l}\text { Estudo de usuários } \\
\text { enfoque na construção } \\
\text { coletiva, crítica e intera- } \\
\text { cionista entre usuário e } \\
\text { centro de informação. } \\
\text { Estudos aproximativos } \\
\text { entre o desenvolvimento } \\
\text { tecnológico e social na } \\
\text { construção da informação. } \\
\text { A concepção sócio-intera- } \\
\text { cionista da informação, } \\
\text { especialmente a partir da } \\
\text { elaboração dos processos } \\
\text { de mediação e serviços de } \\
\text { informação. }\end{array}$ \\
\hline
\end{tabular}

Fonte: Silva, J. (2014, p. 117). 
Silva, J. (2014, p. 181) considera que o conceito social de informação é um dos grandes desafios da CI sob as seguintes perspectivas:

[...] pensar uma prática investigativa de cunho social mais consistente na área; desenvolver uma perspectiva social que permita um diálogo mais horizontalizado com outras áreas; promover autonomia científica a CI evitando que este campo não se situe apenas como um apropriadora [sic] de conceitos de outras áreas; concatenar os conhecimentos científico e social, consolidando uma unidade científico-social; pensar a informação no contexto da construção social e não da diminuição de incertezas ou da transferência de informação; aproximar as relações humanas e alteritárias entre informação e conhecimento; constituir subsídios para promover uma autonomia mais efetiva ao usuário no processo de construção da informação.

O conceito social de informação foi empreendido de forma mais concreta a partir da década de 1990: Hjørland e Albrechtsen (1995), Capurro (2003), Frohmann (2008), Rendón Rojas (2005), entre outros. Nesse cenário, a tendência atual é de evolução do conceito de informação na área da CI para uma acepção puramente subjetiva (ou relativa) e forçosamente social. Nesse sentido, o sistemismo de Mario Bunge, foco deste artigo, está em flagrante conflito com a tendência, como discutimos a seguir.

Entende-se que os estudos de Hjørland e Albrechtsen (1995) e de Frohmann (2008) corroboram essa visão subjetivista-social exclusiva. Hjørland e Albrechtsen (1995) identificaram a existência de diferentes entendimentos do que seja informação para grupos específicos de atores que se relacionam com a informação. Os estudos revelam que, ao resgatar a ideia de subjetividade, há ênfase para o papel ativo dos sujeitos que atuam no âmbito dos sistemas de informação e para além destes. E para Frohmann (2008) o conceito de informação é conjugado com os campos que configuram as características sociais da informação. São eles: o institucional, o tecnológico, o político, o econômico e o cultural.

Todo esse esforço de conceituação, no entanto, parece menosprezar o fato de que informação é um termo polissêmico e preexistente à área. Bunge (1990, p. 593) aponta uma “[...] alegre confusão sobre os múltiplos significados da palavra 'informação' [...]" e distingue “[...] sete conceitos designados por essa palavra de aparência inocente $[\ldots .$.$] ":$ 


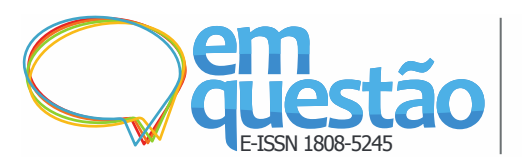
a) significado ou informação semântica;
b) “informação" genética (estrutura do material genético);
c) sinal;
d) mensagem transportada por um sinal codificado por pulso;
e) quantidade de informação transportada por um sinal em um sistema;
f) conhecimento e;
g) comunicação do conhecimento via comportamento social envolvendo um sinal.

O Quadro 1 parece indicar um abandono gradual de alguns dos primeiros significados acima para concentrar-se no primeiro e nos 2 últimos. Isso pode tornar-se um problema se a área pretende alienar parte dos significados - como, por exemplo, quando Le Coadic (1996, p. 5) repete a definição de Ruyer (1954) que restringe informação àquilo que é comunicado entre pessoas: “[...] é um significado transmitido a um ser consciente por meio de uma mensagem inscrita em um suporte espaço-temporal: impresso, sinal-elétrico, onda sonora, etc.”.

Ao sancionar a alienação de alguns significados de informação, sem sequer cogitar quem (qual área) deveria dedicar-se aos demais, a CI implicitamente se isola dos demais campos da ciência, já que algum outro campo fatalmente examinará esse tipo de informação. Essa condição é perigosa para a área, pois uma das características de um campo científico da ciência fatual (i.e., não formal) é a contiguidade com outros campos (BUNGE, 2005), condição que não é cumprida, por exemplo, pelas pseudociências.

Além da alienação de parte das acepções de informação, a tendência atual da área pode alienar pesquisadores, dependendo da visão de mundo que esposam. A definição citada por Le Coadic (1996), por exemplo, caracteriza uma visão de mundo idealista, na medida em que sugere que a informação não existe em si; só existe quando alguém a pensa.

Autores como Albrechtsen, Capurro, Hjørland - citados no Quadro 1 usam bases teóricas que, na tipologia de visões de mundo de Creswell (2007), caracterizam o construtivismo social, cujas assunções filosóficas, em alguns teóricos, incluem o postulado de que não existe realidade externa ao sujeito 
cognoscente. Pesquisadores afiliados filosoficamente ao realismo científico, que identifica a realidade com as coisas concretas (BUNGE, 2005), não encontram bases teóricas adequadas entre as correntes dominantes na CI.

A tentativa de conduzir pesquisa realista-científica usando o paradigma atualmente preponderante na área levaria ao que Silva Triviños (1987) já denominava "indisciplina intelectual" ou falta de coerência entre suportes teóricos. Nesse sentido, este artigo apresenta a filosofia de Mario Bunge como alternativa teórico-metodológica realista para a pesquisa em CI. A próxima seção apresenta a demarcação científica segundo Bunge.

\section{A demarcação científica segundo Bunge}

Bunge (1972) descreve duas características gerais do conhecimento científico: a racionalidade e a objetividade. No âmbito da racionalidade, o conhecimento não consiste apenas em fenômenos psíquicos ou em crenças dos cientistas; consiste de construtos formulados mediante atividades psíquicas, mas que não se reduzem a elas. A objetividade refere-se à maneira impessoal (os enunciados científicos não contêm opiniões ou sentimentos dos sujeitos que os formulam ou os compreendem) e intersubjetivamente controlável sob o objeto de estudo.

A proposição é de que as ideias e teorias devem poder ser testadas. A intersubjetividade não vale por si mesma, mas como indicador da objetividade, pois a realidade não é sempre como parece aos nossos sentidos (CUPANI; PIETROCOLA, 2002).

Bunge foi crítico implacável do positivismo, ainda que seja seu herdeiro na tradição da ciência, e considera insuficiente o critério de demarcação de Popper, o falsacionismo ou a necessidade de qualquer proposição científica ser testável, sujeita a ser falsificada (ou falseada). Uma ideia é científica se e somente se (a) é precisa, (b) é compatível com a maior parte do conhecimento científico relacionado e (c) tem consequências empiricamente contrastáveis (BUNGE, 2005).

Para Bunge $(2012,2014)$ o conhecimento avança encontrando verdades, confirmando conjecturas, especialmente hipóteses sobre os mecanismos em 
ação. É uma busca pelo saber autêntico sobre o mundo real, com auxílio do método científico. O saber científico se supõe de uma coerência lógica, devendo ser objeto de debate racional em uma comunidade de pesquisadores. A ciência básica é definida como um sistema de campos fatuais de pesquisa científica que têm os seguintes condicionantes para sua existência (BUNGE, 2005):

a) uma comunidade científica;

b) uma sociedade que acolhe ou pelo menos tolera a atividade dessa comunidade;

c) um domínio ou universo de discurso do campo científico;

d) um fundamento filosófico realista, com componentes ontológico, epistemológico e ético;

e) um fundamento formal composto por teorias lógicas e matemáticas atualizadas;

f) um fundamento específico do campo, composto de dados, hipóteses e teorias razoavelmente atuais e confirmados, ainda que testáveis, bem como métodos de pesquisa razoavelmente eficazes obtidos em campos relacionados;

g) uma problemática, compatível com o universo de discurso;

h) um fundamento cognitivo histórico, feito de teorias, hipóteses e dados atualizados e testáveis obtidos anteriormente por membros da comunidade;

i) os objetivos de pesquisa dos membros da comunidade;

j) a metodologia do campo, composta exclusivamente de procedimentos rastreáveis e explicáveis, começando pelo método científico geral.

Além disso, um campo científico deve ter ao menos mais um outro campo contíguo, com o qual compartilhe parte de seu domínio e fundamentos. Campos do conhecimento que não satisfazem as condições acima são ditos não científicos, por exemplo: a teologia e a crítica literária, enquanto os que as satisfazem aproximadamente podem configurar uma protociência, como a economia e a ciência política ou, se avançam para o cumprimento pleno, 
caracterizam uma ciência emergente como a psicologia e a sociologia (BUNGE, 2005).

A delimitação bungeana caracteriza o que é ciência e permite diferenciar os campos científicos daqueles que se anunciam científicos sem o ser: as pseudociências. A abordagem científica bungeana é o sistemismo, delineado a seguir.

\section{0 sistemismo de Bunge}

Esta seção associa o realismo científico, a epistemologia bungeana, ao sistemismo, sua ontologia. Depois, compara o sistemismo a duas outras correntes filosóficas amplas: o individualismo e o holismo. Os fundamentos do sistemismo são apresentados a seguir: postulados, redução sistemista ou modelo de sistema e sete regras metodológicas gerais para empreender pesquisa sistêmica.

\subsection{Sistemismo e Realismo Científico: Ontologia e Epistemologia}

O realismo científico é a epistemologia que Bunge adota, tendo como fundamento ontológico o sistemismo. A ontologia estuda o ser, a essência das coisas, portanto precede a epistemologia, que estuda a cognição e o conhecimento (Bunge, 2005). Para enfatizar o contraste com as abordagens antirrealistas, Bunge (1985, p. 55) afirma que o realismo científico

[...] não é uma fantasia inventada por filósofos desconectados da realidade. Pelo contrário, é a epistemologia inerente à investigação científica e técnica. De fato, esta consiste em estudar e modificar o mundo real, não em criar mundos imaginários.

E complementa (BUNGE, 1990, p. 613, tradução nossa):

Após um século de crescimento vigoroso de uma ciência social genuína, o antirrealismo está em agitação no campo dos estudos sociais. Estruturalistas, interacionistas simbólicos, etnometodologistas, fenomenologistas e vários outros nos asseguram de que não há mundo real independente do sujeito cognoscente. Eles nos contam que há tantos mundos quantos são os sujeitos, cada um dos quais constrói sua própria realidade e, em 
particular, a sua própria sociedade. As consequências metodológicas são óbvias: vale tudo, existem várias "racionalidades", nenhuma das quais é superior às outras, e não há necessidade de indicadores objetivos, muito menos de testes empíricos ${ }^{2}$.

Reconhece-se em Bunge a preocupação com o desenvolvimento da ciência e "[...] admite-se como legítima a necessidade de um enfoque realista na divulgação científica, sendo esta formal ou não, por seu apelo de utilidade e praticidade [...]" (WESTPHAL; PINHEIRO, 2004, p. 595). Busca-se produzir explicações para fatos: “[...] ao procurar lançar hipóteses, ou seja, ao produzir teorias, a ciência se propõe a organizar explicações cada vez mais sofisticadas do mundo [...]" (CUPANI; PIETROCOLA, 2002, p. 120).

A epistemologia bungeana, fundada no realismo científico, sustenta a investigação de sistemas a partir da síntese do todo conjugada à análise das partes componentes e suas relações entre si e com o entorno. A abordagem bungeana é contrastada a seguir com correntes amplas que buscam explicações baseadas apenas no todo ou apenas nas partes.

\subsection{Contraste do Sistemismo com o Individualismo e o Holismo}

Bunge (2000) apresenta seu sistemismo como alternativa e conjugação de duas correntes filosóficas amplas: o individualismo e o holismo. $\mathrm{O}$ individualismo, que embasa a ciência analítica, “[...] enfoca a composição de sistemas e se recusa a admitir quaisquer entidades supraindividuais ou suas propriedades [...]" (BUNGE, 2003. p. 38). O holismo "[...] aborda sistemas como totalidades e se recusa a analisá-las e a explicar a emergência e o colapso das totalidades em termos de seus componentes e as interações entre eles [...]" (BUNGE, 2003. p. 38). Ao criticar simultaneamente o individualismo e o holismo,

[...] refuta-se a negativa individualista a reconhecer a existência de entidades supraindividuais e a negativa holista a analisar sistemas a partir de seus indivíduos e suas interações entre si e com o ambiente. Conjugam-se a síntese holista, caracterizada no reconhecimento da existência do todo, e a análise individualista, típica das ciências naturais (SILVA, L., 2014, p. 45-46). 
A teoria sistêmica de Bunge aqui exposta difere das teorias de sistemas conhecidas na CI, como a de Bertalanffy, citada por Araújo (2009) como uma das seis correntes teóricas da área. Bunge (2003) considera a teoria de Bertalanffy holista, pois evita a verificação empírica em favor de descrições no nível do sistema, usando sistemas de equações diferenciais etc. Ou seja, aborda o sistema como um todo, mas não considera a análise da sua totalidade em termos dos seus componentes e da interação entre eles. O Quadro 2 sumaria e caracteriza essas três ontologias: (1) individualismo, (2) holismo e (3) sistemismo.

Quadro 2 - Ontologias e suas correspondentes epistemologias e metodologias

\begin{tabular}{|l|l|l|l|l|}
\hline Ontologia & Epistemologia & Metodologia & Slogan & Autores e ideias (exemplos) \\
\hline Individualismo & $\begin{array}{l}\text { Racionalismo } \\
\text { ou empirismo }\end{array}$ & $\begin{array}{l}\text { Análise: mi- } \\
\text { crorredução }\end{array}$ & $\begin{array}{l}\text { Divide } \\
\text { et } \\
\text { impera. }\end{array}$ & $\begin{array}{l}\text { Cartesianismo; Adam Smith - o } \\
\text { interesse individual é que move a } \\
\text { economia a sociedade; Karl } \\
\text { Popper - o conhecimento humano } \\
\text { resulta de conhecimentos } \\
\text { individuais. }\end{array}$ \\
\hline Holismo & Intuicionismo & $\begin{array}{l}\text { Síntese: ma- } \\
\text { crorredução }\end{array}$ & $\begin{array}{l}\text { Conjuga } \\
\text { et } \\
\text { impera. }\end{array}$ & $\begin{array}{l}\text { Parmênides ("tudo é um"); } \\
\text { Bertalanffy e Laszlo, autores de } \\
\text { teorias de sistemas; Luhmann - } \\
\text { eliminação do indivíduo e } \\
\text { reificação das instituições; } \\
\text { gestaltismo. }\end{array}$ \\
\hline Sistemismo & $\begin{array}{l}\text { Realismo } \\
\text { científico }\end{array}$ & $\begin{array}{l}\text { Análise e } \\
\text { síntese }\end{array}$ & $\begin{array}{l}\text { Divide } \\
\text { et } \\
\text { conjuga. }\end{array}$ & $\begin{array}{l}\text { Newton, a quem coube reconhecer } \\
\text { que o sistema solar é mais do que } \\
\text { um agregado de corpos celestes; } \\
\text { Tocqueville, analista histórico } \\
\text { com visão sistêmica. }\end{array}$ \\
\hline
\end{tabular}

Fonte: Kern (2011) em adaptação a partir de Bunge (2003, p. 126).

O sistemismo tem um componente ontológico e um metodológico (BUNGE, 2006). O sistemismo ontológico afirma que o mundo é um sistema e não simplesmente uma coleção de indivíduos ou um bloco sem estrutura. No aspecto metodológico, entende-se que as totalidades são mais bem entendidas por meio da análise (top-down) e os indivíduos, por meio da síntese (bottom-up).

Bunge não é um dos filósofos mais conhecidos na área da CI. Uma rápida pesquisa na Base de Dados Referenciais de Artigos de Periódicos em Ciência da Informação $(\text { BRAPCI })^{3}$ revela apenas 2 ocorrências, contagem 
semelhante à de outros autores realistas como Popper e Lakatos, em contraste com Foucault (62 ocorrências), Deleuze (30), Marx (24), Latour (16) e Kuhn (11). Nesse cenário, este artigo busca dar visibilidade e tornar mais acessível a filosofia bungeana na área da CI.

O sistemismo “[...] não é uma teoria para substituir outras teorias, mas uma estratégia para desenhar projetos de pesquisa cujo intuito é descobrir algumas características de sistemas de um tipo particular [...]" (BUNGE, 2004, p. 191). Não é uma teoria; é uma abordagem para construir teorias, conforme os princípios descritos a seguir.

\subsection{Postulados}

A visão de mundo sistêmica de Bunge (2000) fundamenta-se em cinco postulados:

a) toda coisa, seja concreta ou abstrata, é um sistema ou um componente ou potencial componente de sistema;

b) sistemas têm características sistêmicas (emergentes) que seus componentes não têm;

c) todos os problemas deveriam ser abordados de forma sistêmica em vez de em forma fragmentada;

d) todas as ideias deveriam ser unidas em sistemas (preferencialmente teorias);

e) o teste de qualquer coisa, seja ideia, método ou artefato, supõe a validade de outros itens que são tomados como pontos de referência (benchmark) provisoriamente.

Nessa visão de mundo sistêmica, não há partes isoladas. As partes estão relacionadas entre si na representação de um todo ou totalidade, ou seja, na representação de um sistema concreto, como se discute a seguir. 


\subsection{Modelo CESM de Sistema}

O reducionismo, filosoficamente individualista, reduz a realidade ao tipo de indivíduo que é objeto de estudo. A "redução" holista contempla o todo nãoanalisado. No sistemismo, a operação epistêmica que viabiliza a investigação é a redução ao sistema. Bunge $(1997 ; 2003)$ afirma que um sistema concreto pode ser descrito por meio do modelo Composition, Environment, Structure, Mechanism (CESM):

a) composição: coleção de partes ou elementos componentes. A composição é atômica. Cada componente é um indivíduo ou átomo do sistema (BUNGE, 1979);

b) entorno ou ambiente: coleção de itens externos que atuam ou sofrem ação por algum componente. Esses itens podem ser buscados entre as possíveis origens dos fatos sociais que desencadeiam mudanças em sistemas: ambientais, biopsicológicas, econômicas, políticas e culturais (BUNGE, 2003);

c) estrutura: coleção de ligações entre componentes e entre esses e itens do ambiente;

d) mecanismo: coleção de processos que geram a novidade qualitativa, isto é, que disparam, fomentam ou obstruem as transformações, causando a emergência, crescimento, manutenção ou o colapso do sistema ou de alguma de suas propriedades.

Bunge (2003) apresenta um modelo de empresa como um sistema composto por quadro de funcionários e gerência, tendo como ambiente o governo e o mercado, com relações de trabalho entre os membros da empresa e ligações entre esses e o ambiente, tendo como mecanismo as atividades que geram produtos. A representação via CESM pode ser feita em diversos níveis de sistema. Dessa forma, é possível construir diversos modelos de sistema social por exemplo, famílias e organizações formais - variando o nível de sistema.

CESM é um metamodelo para representar modelos de sistemas de acordo com a redução sistemista da realidade: ao sistema, e não ao indivíduo, 
como na ciência analítica, ou ao todo, como nas abordagens holistas. A próxima seção aborda a condução de pesquisa sistemista, fazendo uso do CESM.

\subsection{Regras metodológicas gerais}

A abordagem de problemas recomendada pelo sistemismo (BUNGE, 1997) pode ser resumida em sete regras metodológicas gerais que complementam os postulados e o modelo CESM acima citados:

a) colocar todo fato social em seu contexto mais amplo (ou sistema);

b) dividir cada sistema em sua composição, ambiente e estrutura;;

c) distinguir os vários níveis de sistema e exibir suas relações;

d) procurar ou conjeturar os mecanismos;

e) verificar a hipótese ou teoria mecanísmica manipulando experimentalmente as variáveis referidas;

f) preferir hipóteses, teorias e explicações mecanísmicas (dinâmicas) às fenomenológicas (cinemáticas) e aos modelos de equilíbrio e descrições de dados;

g) em caso do mau funcionamento do sistema, examinar todas as quatro fontes possíveis (C, E, S, M) e tentar reparar o sistema alterando alguma ou todas as fontes.

Essas regras metodológicas aplicam-se à descrição e investigação de sistemas de informação. A elaboração de modelos CESM requer investigação descritiva e a conjetura e teste de mecanismos constitui pesquisa explicativa. A expressão sistema de informação é usada num sentido amplo, incluindo aspectos sociais de unidades de informação e outros sistemas, e não apenas em seu aspecto técnico, como é frequente (KERN, 2011).

O mecanismo, modus operandi dos sistemas (BUNGE, 2003), é usualmente oculto e precisa ser conjeturado e investigado empiricamente. Composição, ambiente e estrutura, objetos da regra 2 acima, são usualmente detectáveis e, portanto, descritíveis. A descrição e a explicação sistemistas de 
sistemas de informação são exemplificadas a seguir com relatos de pesquisas sobre repositórios institucionais de acesso aberto.

\section{Aplicação: repositórios institucionais em perspectiva sistemista}

Bunge (1997) prescreve, mas não dá diretrizes detalhadas para elaborar a descrição de componentes, itens do ambiente e ligações do sistema. Silva, L. (2014) apresenta um roteiro metodológico para desenvolver essa descrição na área da CI, com objetivo de construir uma descrição sistêmica de um repositório institucional (RI):

a) a seleção de fontes abrangentes;

b) a marcação dos componentes, itens do ambiente e ligações reconhecidos em cada fonte textual pelo pesquisador e/ou grupo de pesquisa;

c) a discussão em grupo dos elementos marcados pelos diferentes pesquisadores;

d) a síntese e consolidação de um modelo de RI para cada texto fonte;

e) a síntese dos modelos parciais em um modelo de RI derivado das análises parciais da literatura;

f) a discussão da síntese desse modelo derivado da literatura com peritos na área;

g) a síntese de um único modelo abrangendo a análise, discussão e consolidação de todas as fontes analisadas.

Figura 1 - Trecho de marcação de termos associados a elementos de (RI): componentes (vermelho), itens do ambiente (verde) e ligações (azul).

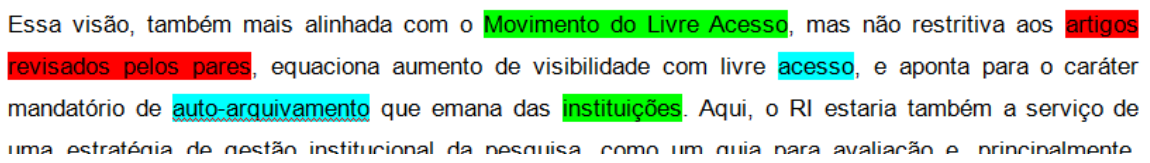

Fonte: Silva, L. (2014).

A marcação é uma tarefa de abstração, portanto objetiva e verificável (diferentemente da interpretação subjetiva). No entanto, a perícia e a atenção de cada modelador influem no resultado. Dessa forma, em espacial quando os 
modeladores são pouco experientes, pode haver diferenças, como exemplifica o Quadro 3, que contém termos marcados por 3 modeladores em um mesmo texto analisado.

Quadro 3 - Termos que representam componentes de um RI marcados em um mesmo texto por três pesquisadores.

\begin{tabular}{|l|l|l|l|}
\hline & Pesquisador 1 & Pesquisador 2 & \multicolumn{1}{|c|}{ Pesquisador 3 } \\
\hline & Artigo científico & Artigo científico & Artigo científico \\
& Artigos revisados & Artigos revisados pelos & Artigos revisados pelos pares \\
& Conteúdos intelectuais & pares & Conteúdos intelectuais \\
& Copyright & Pesquisador individual & Hardware \\
& Metadados & Preprints & Pesquisadores \\
& Pesquisadores & Profissionais de & Preprints \\
& Profissionais de informação & informação e das & Profissionais de informação \\
& e das bibliotecas & bibliotecas & Softwares \\
& Publicação científica & & Usuário \\
\hline
\end{tabular}

Fonte: Silva, L. (2014).

Após discutir em grupo o mérito de cada marcação, os modeladores retêm as marcações apropriadas e agrupam os termos conforme o elemento do sistema que descrevem. No Quadro 3, por exemplo, todas as menções a artigo, conteúdo e preprint representam um mesmo tipo de componente do sistema. A seguir, sintetizam esses elementos da composição, ambiente e estrutura do sistema em modelos parciais, derivados de cada texto analisado.

Os modelos parciais são sintetizados em um único modelo derivado da literatura, que é discutido com os peritos entrevistados. A crítica dos peritos permite preencher lacunas, revelar elementos que a literatura analisada não revelou. A reelaboração do modelo, incluindo a crítica dos peritos, leva ao modelo de RI representado graficamente na Figura 2. 
Figura 2 - Representação gráfica do sistema RI

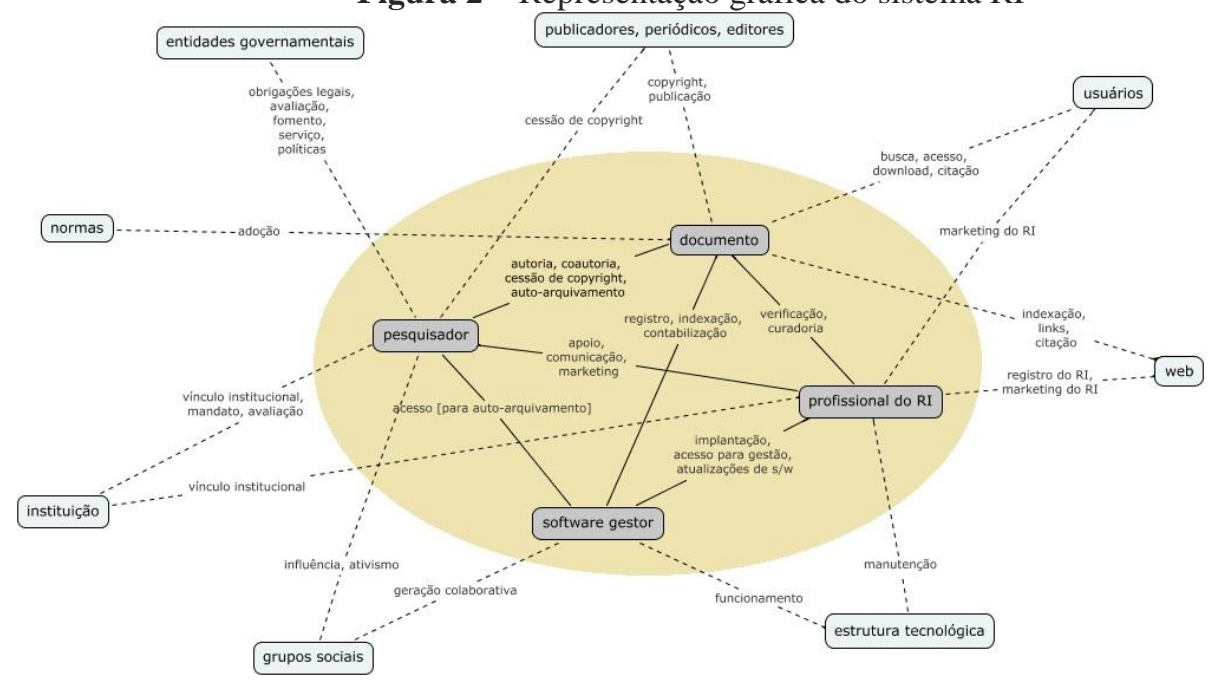

Fonte: Silva, L. (2014).

A descrição dos aspectos detectáveis do sistema corresponde às primeiras etapas metodológicas do sistemismo. Essa descrição é requisito para empreender as próximas etapas, que tratam de conjeturar e testar mecanismos.

Bunge (1997) recomenda representar mecanismos com o uso de diagramas de Boudon-Coleman, como o da Figura 3. Esses diagramas relacionam eventos no nível do sistema com suas causas e efeitos no nível do indivíduo componente do sistema. Também é possível conjeturar explicações relacionando eventos nos níveis do sistema e seu supersistema. Cada seta representa um elo causal que pode ser verificado em uma ou mais pesquisas experimentais.

Figura 3 - Diagrama de Boudon-Coleman para o mecanismo "Asfixia do RI por indexação dificultada por metadados".

\begin{tabular}{|ll}
\begin{tabular}{|l} 
Nivel macro \\
(sistema)
\end{tabular} & $\begin{array}{l}\text { Adoção do software de } \\
\text { gestão DSpace }\end{array}$ \\
$\begin{array}{l}\text { Nível micro } \\
\text { (indivíduo) }\end{array}$ & $\begin{array}{l}\text { Uso de Dublin Core para } \\
\text { especificação de metadados }\end{array}$
\end{tabular}

Fonte: Elaborado pelos autores. 
Na Figura 3, o nível macro diz respeito ao sistema, ao RI. O nível micro corresponde a um indivíduo do sistema - no caso, o software gestor representado na Figura 2. Seria uma mera conjetura de funcionamento, se não houvesse já sido testada e confirmada.

Arlitsch e O'Brien (2012) estudaram as taxas de indexação de documentos em repositórios pelo mecanismo de busca Google Scholar (https://scholar.google.com). Verificaram a hipótese de que o motivo seria o uso da especificação de metadados Dublin Core, que “[...] não consegue expressar informação de citações bibliográficas adequadamente para artigos acadêmicos [...]” (ARLITSCH; O'BRIEN, 2012, p. 60).

O estudo não dá indícios de que tenha sido baseado no sistemismo, como de resto não indica fundamento teórico. Talvez por isso sua conclusão seja tímida: “[...] a falta de visibilidade no Google Scholar [...] limitará a capacidade dos RI de desempenhar um papel mais significativo nas taxas de citação [...]" (ARLITSCH; O'BRIEN, 2012, p. 60).

Postulamos que, ao abstrair um modelo CESM de sistema de RI e, a partir dessa redução, formular a conjetura de um mecanismo de decadência compatível com as conclusões do estudo citado de Arlitsch e O'Brien (2012), dispomos da base teórica necessária para enunciar uma conclusão mais aguda: a adoção de Dublin Core para especificar metadados de RI tem o potencial de destruí-lo, já que tem como objetivo a disseminação científica e esta não acontece se os textos científicos não são encontrados pelos potenciais leitores e citantes.

Essa conclusão, no entanto, parecerá contraintuitiva sem uma visão sistêmica dos RI. Afinal, a adoção de um padrão consagrado como Dublin Core dificilmente será contestada a partir de fundamentos disciplinares, filosoficamente individualistas, de relações causa-efeito lineares tais como "adotar padrões implica promover o bom funcionamento". Sistemas complexos, no entanto, soem contrariar expectativas individualistas como o sucesso de RI a partir da adoção de padrões ou de mandatos de autodepósito. A descoberta de mecanismos de crescimento e manutenção efetivos parece requerer mais 
pesquisas, adotando um ponto de vista sistêmico, compatível com a complexidade do sistema.

\section{Considerações finais}

A CI se constitui no pós-II Guerra Mundial, a partir da constatação do excesso de informação e da dificuldade para acessá-la e recuperá-la (BUSH, 1945). Desde então, vem-se consolidando de forma interdisciplinar, não apenas com contribuições de muitas disciplinas, mas oriundas de perspectivas teóricas diversas, inclusive antagônicas.

A consolidação da área não alcançou consenso, até o momento, sequer sobre seu objeto de pesquisa, a informação. Convivem na literatura da CI definições amplas com outras peculiares. Os que tentam abranger a complexidade da questão são raros, como Borko (1968), um autor da área que definiu informação como coisa, processo e conhecimento, e o filósofo Bunge (1990), que a definiu com sete possíveis significados. Assim, permanece o problema da "falta de higiene terminológica" da área, apontado por Hjørland (2014).

Dada a diversidade teórica e metodológica da CI, parece improvável que no futuro breve haja convergência nessas dimensões. Dessa forma, é importante que cada pesquisa faça uso de bases teóricas compatíveis com suas opções metodológicas, para evitar a falta de coerência que Silva Triviños (1987) denominou "indisciplina intelectual". Nesse sentido, este artigo apontou a prevalência de abordagens filosoficamente relativistas na CI e apresentou os fundamentos do sistemismo de Mario Bunge como alternativa epistemologicamente realista para pesquisas com esta posição ontológica.

Foi discutida a questão essencial da demarcação do que é científico segundo Bunge. Ainda, foram delineados os fundamentos do sistemismo: seus postulados e modelo de sistema CESM - composição, ambiente, estrutura e mecanismo.

Entende-se que o objetivo do artigo foi alcançado por meio da discussão teórica e sua principal contribuição foi a demonstração de aplicabilidade na área 
da CI. O artigo concentrou-se nos componentes ontológico e epistemológico que, segundo Bunge (2005), juntamente com o componente ético, fazem parte de um fundamento filosófico realista para um campo da ciência fatual (vide seção 4).

O componente ético é objeto do volume 8 do Treatise on Basic Philosophy de Bunge (1989). Recomenda-se como tema para futuros trabalhos a abordagem de valores, moralidade e ações na área da CI sob essa perspectiva ética realista.

No aspecto metodológico, o artigo apresentou as regras metodológicas gerais da pesquisa sistemista e um roteiro para modelagem dos aspectos detectáveis dos sistemas: composição, ambiente e estrutura, já que o aspecto que completa o modelo CESM, o mecanismo, é usualmente oculto e precisa ser conjeturado, bem como testado empiricamente. O roteiro foi exemplificado com um modelo de sistema de RI.

Reconhece-se em Bunge a preocupação com o avanço da ciência e sua divulgação. Postula-se a epistemologia proposta por Bunge como uma teoria emergente na CI, capaz de contribuir para o desenvolvimento da área a partir de uma nova redução: ao sistema, diferentemente da redução ao indivíduo da ciência tradicional, porém mantendo a busca por causas e efeitos, agora explicados a partir de mecanismos de funcionamento conforme o modelo CESM. Nesse contexto, espera-se que este artigo estimule a elaboração de novas pesquisas sistêmicas em geral, e na CI em particular.

Finalmente, cabe assinalar que este estudo é conduzido no grupo de pesquisa Informação, Tecnologia e Sociedade, que abriga pesquisadores com afiliações filosóficas diversas e discute o uso de diferentes paradigmas, métodos e técnicas de pesquisa, inclusive promovendo encontros periódicos (SILVA, A. et al., 2014). A tentativa de desenvolver colaboração em pesquisa através da divisão entre realismo e antirrealismo está em concordância com Ziman (2000), quando afirma que há conhecimentos valiosos estabelecidos a partir de pontos de vista especializados e que é necessário muito trabalho nas fronteiras intelectuais para traduzir ideias, de maneira consistente e coerente, de uma linguagem especializada a outra. 


\section{Agradecimentos}

Agradecemos à CAPES pela concessão de bolsa de pós-doutorado sênior no Consejo Superior de Investigaciones Científicas de Madrid e ao CNPq por apoio a projeto científico no âmbito do Edital Universal, ambos para o terceiro autor.

\section{Referências}

ARANHA, Maria Lúcia de Arruda; MARTINS, Maria Helena Pires. Temas de filosofia. 2. ed. São Paulo: Moderna, 1999.

ARAÚJO, Carlos Alberto Ávila. Correntes teóricas da ciência da informação. Ciência da Informação, Brasília, v. 38, n. 3, p. 192-204, dez. 2009.

ARLITSCH, Kenning; O'BRIEN, Patrick S. Invisible institutional repositories: addressing the low indexing ratios of IRs in Google Scholar. Library Hi Tech, [S.1.] v. 30, n. 1, p. 60-81, 2012.

BORKO, H. Information science: what is it? American Documentation, Washington, v. 19, n. 1, p. 3-5, Jan. 1968.

BUNGE, Mario. A systemic perspective on crime. In: WIKSTRÖM, Per-Olof H.; SAMPSON, Robert J. (Ed.). The explanation of crime: context, mechanisms and development. Cambridge: Cambridge University, 2006. p. 830 .

BUNGE, Mario. Diccionario de filosofía. 3. ed. Buenos Aires: Siglo XXI, 2005.

BUNGE, Mario. Emergence and convergence: qualitative novelty and the unity of knowledge. Toronto: University of Toronto, 2003.

BUNGE, Mario. Filosofia para médicos. Barcelona: Gedisa, 2012.

BUNGE, Mario. How does it work? The search for explanatory mechanisms. Philosophy of the Social Sciences, Waterloo, v. 34, n. 2, p. 182-210, June 2004.

BUNGE, Mario. La ciencia: su método y su filosofía. Buenos Aires: Siglo Veinte, 1972.

BUNGE, Mario. Las pseudociencias ¡Vaya timo! Pamplona: Laetoli, 2014.

BUNGE, Mario. Mechanism and explanation. Philosophy of the Social Sciences, Waterloo, v. 27, n. 4, p. 410-465, Dec. 1997. 
BUNGE, Mario. Racionalidad y realismo. Madrid: Alianza, 1985.

BUNGE, Mario. Systemism: the alternative to individualism and holism. Journal of Socio-Economics, [Beer Sheva], v. 29, n. 2, p. 147-157, 2000.

BUNGE, Mario. Treatise on basic philosophy. Dordrecht: D. Reidel, 1979. (Ontology II: a world of systems, v. 4).

BUNGE, Mario. Treatise on basic philosophy. Dordrecht: Kluwer, 1989. (Ethics: the good and the right, v. 8).

BUNGE, Mario. Wand and Weber on information systems. In:

WEINGARTNER, Paul; DORN, Georg J. W. (Ed.). Studies on Mario Bunge's treatise. Amsterdam: Rodopi, 1990. p. 593-595.

BUSH, Vannevar. As we may think. The Atlantic Monthly, Boston, v. 176, n. 1, p. 101-108, 1945.

CAPURRO, Rafael. Epistemologia e ciência da informação. In: ENCONTRO NACIONAL DE PESQUISA EM CIÊNCIA DA INFORMAÇÃO, 5., 2003, Belo Horizonte. Anais... Belo Horizonte: ANCIB, 2003. p. 1-28.

CHINAZZO, Suzana Salete Raymundo. Epistemologia das ciências sociais. Curitiba: Intersaberes, 2013.

CRESWELL, John W. Projeto de pesquisa: métodos qualitativo, quantitativo e misto, 2. ed. Porto Alegre: Artmed, 2007.

CUPANI, Alberto Osmar; PIETROCOLA, Maurício. A relevância da epistemologia de Mario Bunge para o ensino de ciências. Caderno Brasileiro de Ensino de Física, Florianópolis, v. 19, n. esp., p. 100-125, jun. 2002.

FROHMANN, Bernd. O caráter social, material e público da informação. In: FUJITA, Mariangela Spotti Lopes; MARTELETO, Regina Maria; LARA, Marilda Lopes Ginez de (Org.). A dimensão epistemológica da ciência da informação e suas interfaces técnicas, políticas e institucionais nos processos de produção, acesso e disseminação da informação. São Paulo: Cultura Acadêmica, 2008. p. 19-34.

GRANT, Maria J.; BOOTH, Andrew. A typology of reviews: an analysis of 14 review types and associated methodologies. Health Information and Libraries Journal, Oxford, v. 26, n. 2, p. 91-108, June 2009. Disponível em: <http://www.ncbi.nlm.nih.gov/pubmed/19490148>. Acesso em: 03 nov. 2015.

HJØRLAND, Birger. Information science and its core concepts: levels of disagreement. In: IBEKWE-SANJUAN, Fidelia; DOUSA, Thomas M. (Ed.). Theories of information, communication and knowledge: a multidisciplinary 
approach. London: Springer, 2014. chap. 9, p. 205-235. (Studies in History and Philosophy of Science, v. 34).

HJØRLAND, Birger; ALBRECHTSEN, Hanne. Toward a new horizon in information science: domain-analysis. Journal of the American Society for Information Science, New York, v. 46, n. 6, p. 400-425, July 1995.

KERN, Vinícius Medina. O sistemismo de Bunge: fundamentos, abordagem metodológica e aplicação a sistemas de informação. In: ENCONTRO NACIONAL DE PESQUISA EM CIÊNCIA DA INFORMAÇÃO, 12., 2011, Brasília. Anais... Brasília: Thesaurus, 2011. p. 2693-2709.

LE COADIC, Yves-François. A ciência da informação. Brasília: Briquet de Lemos, 1996.

LIMA, José Leonardo Oliveira; ALVARES, Lilian. Organização e representação da informação e do conhecimento. In: ALVARES, Lilian (Org.). Organização da informação e do conhecimento: conceitos, subsídios interdisciplinares e aplicações. Jandira: B4, 2012. p. 21-47.

PINHEIRO, Lena Vania Ribeiro. Campo interdisciplinar da ciência da informação: fronteiras remotas e recentes. Investigación Bibliotecológica, [S.1.], v. 12, n. 25, p. 132-163, 1998.

PINHEIRO, Lena Vania Ribeiro. Evolução e tendências da ciência da informação, no exterior e Brasil: quadro comparativo a partir de pesquisas históricas e empíricas. In: ENCONTRO NACIONAL DE PESQUISA EM CIÊNCIA DA INFORMAÇÃO, 6., 2005, Florianópolis. Anais... Florianópolis: UFSC, 2005. 1 CD-ROM.

RABELLO, Rodrigo. A ciência da informação como objeto: epistemologias como lugares de encontro. Perspectivas em Ciência da Informação, Belo Horizonte, v. 17, n. 1, p. 2- 36, jan./mar. 2012.

RENDÓN ROJAS, Miguel Angel. Relación entre los conceptos: información, conocimiento y valor: semejanzas y diferencias. Ciência da Informação, Brasília, v. 34, n. 2, p. 52-61, maio/ago. 2005.

RUYER, Raymond. La cybernétique et l'origine de l'information. Paris: Flammarion, 1954.

SALDANHA, Gustavo Silva. Thomas Kuhn na epistemologia da ciência da informação: uma reflexão crítica. Informação \& Informação, Londrina, v. 13, n. 2, p. 54-78, jul./dez., 2008. Disponível em:

<http://www.uel.br/revistas/uel/index.php/informacao/article/view/1814>. Acesso em: 09 abr. 2015.

SARACEVIC, Tefko. Ciência da informação: origem, evolução e relações. 
Perspectivas em Ciência da Informação, Belo Horizonte, v. 1, n. 1, p. 41-62, jan./jun. 1996.

SHERA, J. H.; CLEVELAND, D. B. History and foundations of information science. Annual Review of Information Science and Technology, White Plains, v. 12, p. 249-275, 1977.

SILVA, Ana Claudia Perpétuo de Oliveira da et al. Estudos e ações em informação e educação - 2013. Encontros Bibli, Florianópolis, v. 19, n. 39, p. 269-300, 2014.

SILVA, Jonathas Luiz Carvalho. Múltiplas interlocuções da informação no campo da ciência da informação no âmbito dos fundamentos técnicopragmáticos, humanos e científicos. 2014. 491 f. Tese (Doutorado em Ciência da Informação) - Programa de Pós-Graduação em Ciência da Informação, Universidade Federal da Bahia, Salvador, 2014.

SILVA, Luciana Mara. Repositório institucional como sistema técnico-social: composição, ambiente e estrutura. 2014. 149 f. Dissertação (Mestrado em Ciência da Informação) - Programa de Pós-Graduação em Ciência da Informação, Universidade Federal de Santa Catarina, Florianópolis, 2014. Disponível em: <http://tede.ufsc.br/teses/PCIN0100-D.pdf>. Acesso em: 05 ago. 2015.

SILVA TRIVIÑOS, Augusto Nibaldo. Introdução à pesquisa em ciências sociais: a pesquisa qualitativa em educação. São Paulo: Atlas, 1987.

WESTPHAL, Murilo; PINHEIRO, Thais Cristine. A epistemologia de Mario Bunge e sua contribuição para o ensino das ciências. Ciência \& Educação, São Paulo, v. 10, n. 3, p. 585-596, 2004.

ZIMAN, John. Real science: what it is and what it means. Cambridge: Cambridge University, 2000.

\title{
Mario Bunge's systemism as theoretical-methodological
}

\section{foundation for information science research}

\begin{abstract}
This paper aims at bringing Mario Bunge's theoretical contributions to the scientific enterprise into the realm of Information Science. The study is justified by the area's interdisciplinary nature and its constant need for
\end{abstract}


interaction with other knowledge areas. It is a theoretical essay based on the analysis of information science concepts and on Bunge's systemism. We further extend the study with the application of fundamentals of systemism in two related studies, one descriptive, other explanatory, on institutional repositories, thus exemplifying research conduction under the fundamental epistemic operation in systemism: the reduction to the system.

Keywords: Systemism. Mario Bunge. Scientific realism. Epistemology. Research methodology.

Recebido: 08/09/2015

Aceito: 19/02/2016

\footnotetext{
${ }^{1}$ Information science is that discipline that investigates the properties and behavior of information, the forces governing the flow of information, and the means of processing information for optimum accessibility and usability. It is concerned with that body of knowledge relating to the origination, collection, organization, storage, retrieval, interpretation, transmission, transformation, and utilization of information

${ }^{2}$ After a century of vigorous growth of genuine social science, anti-realism is on the rampage in the field of social studies. Structuralists, symbolic interactionists, ethnomethodologists, phenomenologists and several others assure us that there is no real world independent of the knowing subject. They tell us that there are as many worlds as subjects, every one of whom constructs his own reality and, in particular, his own society. The methodological consequences are obvious: anything goes, there are multiple "rationalities", neither of which is superior to the others, and there is no need for objective indicators, let alone for empirical tests.

${ }^{3}$ Buscas simples em <http://www.brapci.ufpr.br>.
} 